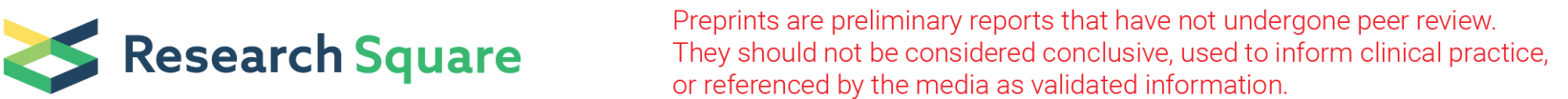 \\ Detection and Quantification of EBV, CMV and HHV- 6 DNA in Stomach Frozen Tissue of Gastritis and Gastric Cancer Patients
}

\section{Behrang Sarshari}

Tarbiat Modares University Faculty of Medical Sciences

Seyed Reza Mohebbi ( $\nabla$ srmohebbi@gmail.com )

Shahid Beheshti University of Medical Sciences Research Institute for Gastroenterology and Liver

Diseases https://orcid.org/0000-0002-7020-7889

\section{Mehrdad Ravanshad}

Tarbiat Modares University Faculty of Medical Sciences

\section{Shabnam Shahrokh}

Shahid Beheshti University of Medical Sciences Research Institute for Gastroenterology and Liver Diseases

\section{Hamid Asadzadeh-Aghdaei}

Shahid Beheshti University of Medical Sciences Research Institute for Gastroenterology and Liver

Diseases

\section{Mohammad Reza Zali}

Shahid Beheshti University of Medical Sciences Research Institute for Gastroenterology and Liver Diseases

\section{Research}

Keywords: EBV, HHV-6, CMV, Gastric cancer, Gastritis, viral copy number

Posted Date: October 5th, 2021

DOl: https://doi.org/10.21203/rs.3.rs-898536/v1

License: (c) (i) This work is licensed under a Creative Commons Attribution 4.0 International License. Read Full License 


\section{Abstract}

\section{Background}

Human herpes viruses (HHVs) are among the most common infectious agents detected in the gastrointestinal tract that might be involved in oncogenesis and other gastrointestinal disorders. Although the link between the EBV and gastric cancer (GC) has been established, role of the viruses in various stomach diseases remain unknown.

\section{Methods}

The frequencies and viral copy number of EBV, CMV and HHV-6 among 50 GC tumors and 105 gastritis tissues were measured by quantitative real-time PCR.

Results

EBV, CMV and HHV- 6 DNA were detected in $30(60 \%), 7(14 \%)$ and $9(18 \%)$ of the tumor specimens, while in gastritis patients were 20 (19\%), 13 (12.3\%) and 16 (15.2\%) respectively. The EBV frequency was significantly higher in GC compared with gastritis patients $(p<0.0001)$. Viral load in both $G C$ and gastritis groups was higher in either tumor or gastritis lesion compared with matched adjacent normal tissue. This study showed a clear association between GC with both EBV $(p=0.0268)$ and CMV $(p=0.0012)$. In addition, analyzes revealed a strong association between the EBV, CMV and HHV- 6 with gastritis $(p=0.0026, p<0.0001$ and $p=0.0405$ respectively).

Conclusions

Our results suggest that these three viruses might contribute to induction and development the gastritis and GC.

\section{Background}

Gastric cancer (GC), one of the most common cancers, is the fourth leading cause of cancer deaths worldwide (1). Also, gastritis, one of the other stomach-related disorders, is estimated to affect about $50 \%$ of the world population with different degrees (2). To date, many types of viruses including several human herpes viruses (HHVs) detected in the disorders related gastrointestinal system (3). HHVs have the capacity to cause both forms of lytic and latent infections. Viral particle production and thus lysis of the host cell can occur in the lytic state. However, during latent state, the infection persistent in a broad range of host cell types, with a limited expression of viral proteins (4). Besides diseases such as infectious mononucleosis (IM), Nasopharyngeal carcinoma (NPC) and Burkitt's lymphoma (BL), approximately $10 \%$ of gastric carcinomas are arising from Epstein-Barr virus (EBV) infection (5). So far, case reports of the association of EBV with acute gastritis published (6-9). However, the role of this virus has not been elucidated in causing gastritis completely. Human cytomegalovirus (HCMV), as another member of the herpesviridea family can infect over $50 \%$ of normal adults by age 40 (10). Meanwhile, the 
published literatures in recent years show a probable association between this virus and several different cancers including colorectal cancer (11), GC (12), glioblastoma (13), breast cancer (14) and also gastrointestinal disorders (15). In addition to creating roseola, a self-limited disease in children, encephalitis is another disease with a possible role of human herpesvirus 6 (HHV-6) (16). The correlation of HHV- 6 with the gastrointestinal tract diseases is still under investigation and its role in stomach disorders is unclear. In this study, we aimed to evaluate viral load corresponding to EBV, CMV and HHV-6 in the stomach tissue of GC and gastritis patients, to further reveal the possible association between these viruses and the related disorders.

\section{Methods}

\section{Patients and Clinical Samples}

Fifty GC individuals ( 37 males and 13 females, mean age and standard deviation, $66 \pm 12.4$ years) and one hundred and five chronic gastritis patients (53 males and 52 females, mean age and standard deviation, $45 \pm 15.5$ years) were included in this study (Table 1). Gastric tumors and gastritis biopsies with paired adjacent normal tissues (taken at least $3 \mathrm{~cm}$ distance from the lesion margin) were taken from patients. All specimens were then washed twice with phosphate-buffered saline (PBS) for to clean from external fluids and subsequently stored at $-70^{\circ} \mathrm{C}$ until DNA extraction and further application of realtime PCR (RT-PCR). This study was approved by the ethical review committee of the research institute and all patients and controls gave their informed consent.

\section{Viral Genome Quantification}

Viral DNA was extracted from tumor and normal tissue samples using a QIAamp DNA mini kit (QIAGEN, Hilden, Germany) according to the manufacturer's instructions. The concentration and purity of the extracted DNA samples were evaluated in a nanodrop 2000 spectrophotometer (Thermo, MA, USA). The endogenous b-actin gene were used as a criteria for evaluation quality of the extracted DNA and presence of PCR inhibitors during amplification. The real-time PCRs were carried out using a multiplex TaqMan PCR for EBV, CMV, and HHV-6. The primers and probes used for the assay have been described previously (17). The PTG19 plasmid containing target fragments for each virus was prepared and used as a standard for CMV, EBV and HHV-6 DNA quantification. To construct the standards, DNA from the CMV, EBV and HHV-6 positive samples was amplified with primers used in The multiplex real-time PCR assay and PCR products (EBV: 90bp, CMV: 200bp and HHV-6: 223bp) TA cloned in pTG19-T vector (Vivantis, Malaysia) using T4 ligase and Top10 E. coli strain for cloning. The sequencing results confirmed that each of which the recombinant plasmids carried a single copy of target fragment.

The concentration of recombinant plasmids was estimated by measuring the absorbance at $260 \mathrm{~nm}$ and the corresponding copy number was calculated. For quantification of EBV viral load, a 10-fold serial dilution series of the recombinant plasmids $\left(10^{1}-10^{6}\right.$ copies) containing target sequences was used to construct the standard curves. 
Statistical Analysis

The SPSS 21.0 package (SPSS, Chicago, IL, USA) was used for performing statistical analyses and GraphPad Prism 9.0 software (GraphPad Software Inc., La Jolla, CA, USA) was used for constructing graphs. The prevalence of CMV, EBV and HHV-6 infections was evaluated in the compared groups. The differences in the copy number of these three viruses in Gastric cancer and Gastritis, as well as adjacent normal tissue were analyzed using the Mann-Whitney test or Kruskal-Wallis test, due to the incompatibility of the viral copy number with the Gaussian distribution. A p-values < 0.05 was regarded as statistically significant for all tests.

\section{Results}

\section{Prevalence of EBV, HHV-6 and CMV infection in the two groups of gastric cancer and gastritis}

DNA extracted from the $50 \mathrm{GC}$ tissue (group I) and 105 chronic gastritis tissue (group II) was used as a template for multiplex TaqMan-probe-based real-time PCR.

Out of Patients in group I, EBV, CMV and HHV-6 were identified in $30(60 \%), 7(14 \%)$ and $9(18 \%)$ of them, respectively (Fig. 1). Out of 30 patients who were EBV positive, 4 of them had simultaneous HHV- 6 and 6 were coinfected with CMV. Prevalence EBV, CMV and HHV-6 among the patients of group II were 20 (19\%), $13(12.3 \%)$ and 16 (15.2\%) (Fig. 1). 2 of 20 of whom were EBV positive, had simultaneously HHV6 and $\mathrm{CMV}$ infections. Also 2 patients had coinfection with CMV and HHV-6 of total group II. Did not find evidence of effect of gender differences on any viruses frequencies including EBV ( $p=0.895), C M V$ $(p=0.457)$ and HHV-6 $(p=0.174)$ in group I or EBV $(p=0.384), C M V(p=0.139)$ and HHV-6 $(p=0.972)$ in group II.

\section{Viral load in GC tumor and adjacent normal tissue}

The median copy number in EBV, HHV-6 and CMV positive GC tumor was 668.9, 246.5 and 1296 copies/ug DNA (range 11.65-53591, 21.99- 21933 and 62.60-14920 copies/ug total DNA) respectively, while that was 103.3, 92.21 and 0.000 for this viruses in adjacent normal tissues (range 0.000-5396, 0.000-12294 and 0.000-14.93) (Table 2). As mentioned above, the viral copy number in all three viruses was higher in the lesion tissue than in the adjacent normal tissue. However, this difference was only statistically significant for EBV $(p=0.0268)$ and CMV $(p=0.0012)$. No significant difference was found between median copy number of HHV- 6 in GC tumor and paired adjacent normal tissue $(p=0.8515)$ (Fig. 2).

\section{viral load in chronic gastritis and adjacent normal tissue}

We also estimated the viral load in gastritis tissue and paired adjacent normal tissue and observed a different level of copy number for all of these viruses. The analysis revealed a significantly higher viral load between these two sections of the stomach tissue in patients (Table 2). 
In gastritis tissue the median copy number for EBV, CMV and HHV-6 was 886.0 (101.0- 7511), 100.0 (23.08- 285.7) and 1594 (140.3-27493) copies/ug DNA respectively, While the median copy number in adjacent normal tissue was 177.8 (21.90-1235), 0.000 (0.000-14.60) and 26.00 (0.000-2561) for EBV, CMV and HHV-6 ( $p=0.0026, p<0.0001$ and $p=0.0405)$ (Fig. 3).

\section{Discussion}

Human herpes viruses are among the most common viral infections worldwide and linked with many malignancies and diseases (18). The role of the EBV is known as cause many cancers, such as nasopharyngeal carcinoma, Hodgkin's lymphoma, Burkitt's lymphoma and gastric carcinoma (19). CMV, another member of the herpesviridae family has been linked to several cancers, including colorectal cancer (11), glioblastoma (13) and lymphatic metastasis(12). To date association EBV and CMV with gastritis have been documented in several case reports or case series $(8,15,20)$. However, there is little information about the occurrence HHV- 6 infection in the gastrointestinal tract, especially gastritis and its role not yet well known.

We detected the EBV in $60 \%$ of GC versus $20 \%$ of gastritis tissue specimens. Differences between observed frequencies in the two groups seems related to the causal role of the virus in GC (Fig. 1). This high positivity rates have also been reported in a study from Portugal with $90.2 \%$ of GC and $27.3 \%$ from the control group. Several other studies have been documented EBV positive rates a range of $1.2 \%$ to $89.2 \%$ in GC (21). However different factors, including study location, the histologic type of GC, PCR method with various sensitive, sex, age, tumor location and tumor-infiltrating lymphocytes may impact on EBV positivity. In this study the frequency of CMV in GC and gastritis patients was $14 \%$ and $12.3 \%$ respectively, which was much lower than the study of L. Zhang et al. with a prevalence of $69 \%$ in GC (12). Whereas, in another study, the CMV positivity was the same as our estimate (14\%) in GC (22). Studies on the prevalence of $\mathrm{CMV}$ in gastritis are limited to case reports and little is known about it. Likewise, the prevalence of HHV- 6 was $18 \%$ in the GC group and $15.2 \%$ in the gastritis group, a higher rate than the two reports conducted by Cantalupo et al. (3.9\%) and Cao et al. (3.5\%) in stomach cancer (23).

Finally, we evaluated viral load for the tumor and gastritis lesion with adjacent normal pairs in two groups I and II, where either tumor or gastritis lesion and matched adjacent normal were positive for EBV, CMV or HHV-6. We found an increase in viral abundance in tumors than adjacent normal samples in most cases (group I). Despite the differences between viral copies number for the three viruses examined, high levels of viral load in the tumor compared to adjacent normal samples shows significant only for CMV and EBV. However, this strikingly different of viral copy number between tumor-adjacent normal pairs could be a strong signal that EBV and CMV are linked to stomach cancer. It should be noted that the association of EBV with GC is already known and has been the subject of intensive research. Whether the observed association between the CMV and GC is a causative or incidental accompaniment still unknown. Although, another aspect of this viral load difference may be due to the presence of infiltrating immune cells in the tumor. Of note, our results are in agreement with previous studies that have shown an association between these two viruses and GC $(12,24)$. In term of HHV-6, Cao et al. has reported a 
significant link with stomach cancer, where it's found in tumor, but absent in their matched adjacent normal samples, while we didn't found significant association (25).

For the group II, also statistical analysis revealed an appreciable and significantly higher copy number of all three viruses in chronic gastritis than in the matched adjacent tissue samples. So far, several case reports have indicated the role of the EBV in causing gastritis $(8,26-29)$. Although, very few case reports have been published regarding the link between the CMV and gastritis $(15,30-32)$, nevertheless no association has been reported between the HHV-6 and gastritis. We have no answer to the question which these viruses how participates in pathogenesis and whether are contributing to creation and development the lesion or being attracted by carrying Inflammatory cells, with a transient presence.

\section{Conclusion}

Viral copy number was performed on tumor and gastritis biopsies, which indicated a significantly higher copy number than that in adjacent normal tissue. There is a strong association between the EBV and CMV with GC, as well as the EBV, CMV and HHV-6 with gastritis. Differences observed in the copy number of these viruses warrants further investigation to determine if a etiological role exists for herpesviruses in GC and gastritis.

\section{Abbreviations}

HHVs: Human herpes viruses; GC: gastric cancer; IM: infectious mononucleosis; NPC: Nasopharyngeal carcinoma; BL: Burkitt's lymphoma; EBV: Epstein-Barr virus; HCMV: Human cytomegalovirus; HHV-6: human herpesvirus 6; PBS: phosphate-buffered saline; RT-PCR: real-time PCR;

\section{Declarations}

\section{Acknowledgements}

Not applicable.

\section{Authors' contributions}

BS carried out most of the experimental work related to optimization of RT-PCR assay, as well as prepared the figures, tables and wrote the manuscript. SRM designed the study, supervised research works and revised the manuscript. MR supervised and reviewed the article and helped the data analysis. HAA collected the samples and demographic data. SS and MRZ helped the data analysis. All authors read and approved the final manuscript.

\section{Funding}

Not applicable 
Availability of data and materials

The datasets used and analyzed during the current study are available from the corresponding author upon reasonable request.

\section{Ethics approval and consent to participate}

Not Applicable.

\section{Consent for publication}

Not applicable

\section{Competing interests}

The authors declare no conflict of interest.

\section{References}

1. Ferlay J, Ervik M, Lam F, Colombet M, Mery L, Piñeros M, et al. Global cancer observatory: cancer today. Lyon, France: international agency for research on cancer. 2018:1-6.

2. Sipponen P, Maaroos H-I. Chronic gastritis. Scandinavian journal of gastroenterology. 2015;50(6):657-67.

3. Shimada T, Nagata N, Okahara K, Joya A, Hayashida T, Oka S, et al. PCR detection of human herpesviruses in colonic mucosa of individuals with inflammatory bowel disease: comparison with individuals with immunocompetency and HIV infection. PloS one. 2017;12(9):e0184699.

4. Traylen CM, Patel HR, Fondaw W, Mahatme S, Williams JF, Walker LR, et al. Virus reactivation: a panoramic view in human infections. Future virology. 2011;6(4):451-63.

5. Jha HC, Pei Y, Robertson ES. Epstein-Barr virus: diseases linked to infection and transformation. Frontiers in microbiology. 2016;7:1602.

6. Cárdenas-Mondragón MG, Carreon-Talavera R, Camorlinga-Ponce M, Gomez-Delgado A, Torres J, Fuentes-Panana EM. Epstein Barr virus and Helicobacter pylori co-infection are positively associated with severe gastritis in pediatric patients. PLoS One. 2013;8(4):e62850.

7. Fasciana T, Capra G, Calà C, Zambuto S, Mascarella C, Colomba C, et al. HELICOBACTER PYLORI AND EPSTEIN-BARR CO-INFECTION IN GASTRIC. HELICOBACTER. 2017;1:73-82.

8. Hisamatsu A, Nagai T, Okawara H, Nakashima H, Tasaki T, Nakagawa Y, et al. Gastritis associated with Epstein-Barr virus infection. Internal Medicine. 2010;49(19):2101-5. 
9. Kartika AV, lizasa H, Ding D, Kanehiro Y, Tajima Y, Kaji S, et al. Application of Biopsy Samples Used for Helicobacter pylori Urease Test to Predict Epstein-Barr Virus-Associated Cancer. Microorganisms. 2020;8(6):923.

10. Al Mana H, Yassine HM, Younes NN, Al-Mohannadi A, Al-Sadeq DW, Alhababi D, et al. The current status of Cytomegalovirus (CMV) prevalence in the MENA region: A systematic review. Pathogens. 2019;8(4):213.

11. Chen H-P, Jiang J-K, Chen C-Y, Chou T-Y, Chen Y-C, Chang Y-T, et al. Human cytomegalovirus preferentially infects the neoplastic epithelium of colorectal cancer: a quantitative and histological analysis. Journal of clinical virology. 2012;54(3):240-4.

12. Zhang L, Guo G, Xu J, Sun X, Chen W, Jin J, et al. Human cytomegalovirus detection in gastric cancer and its possible association with lymphatic metastasis. Diagnostic microbiology and infectious disease. 2017;88(1):62-8.

13. Rahbar A, Orrego A, Peredo I, Dzabic M, Wolmer-Solberg N, Strååt K, et al. Human cytomegalovirus infection levels in glioblastoma multiforme are of prognostic value for survival. Journal of Clinical Virology. 2013;57(1):36-42.

14. Bishop RK, Oseguera CAV, Spencer JV. Human cytomegalovirus interleukin-10 promotes proliferation and migration of MCF-7 breast cancer cells. Cancer cell \& microenvironment. 2015;2(1).

15. Chen D, Zhao R, Cao W, Zhou W, Jiang Y, Zhang S, et al. Clinical characteristics of cytomegalovirus gastritis: A retrospective study from a tertiary medical center. Medicine. 2020;99(5).

16. Berzero G, Campanini G, Vegezzi E, Paoletti M, Pichiecchio A, Simoncelli AM, et al. Human Herpesvirus 6 Encephalitis in Immunocompetent and Immunocompromised Hosts. NeurologyNeuroimmunology Neuroinflammation. 2021;8(2).

17. Wada K, Kubota N, Ito Y, Yagasaki H, Kato K, Yoshikawa T, et al. Simultaneous quantification of Epstein-Barr virus, cytomegalovirus, and human herpesvirus 6 DNA in samples from transplant recipients by multiplex real-time PCR assay. Journal of clinical microbiology. 2007;45(5):1426-32.

18. Slots J. Oral viral infections of adults. Periodontology 2000. 2009;49(1):60-86.

19. Leong MML, Lung ML. The Impact of Epstein-Barr Virus Infection on Epigenetic Regulation of Host Cell Gene Expression in Epithelial and Lymphocytic Malignancies. Frontiers in Oncology. 2021;11:201.

20. Morales-Sánchez A, Torres J, Cardenas-Mondragón MG, Romo-González C, Camorlinga-Ponce M, Flores-Luna L, et al. Detection of Epstein-Barr Virus DNA in gastric biopsies of pediatric patients with dyspepsia. Pathogens. 2020;9(8):623. 
21. Pyo J-S, Kim N-Y, Kang D-W. Clinicopathological Significance of EBV-Infected Gastric Carcinomas: A Meta-Analysis. Medicina. 2020;56(7):345.

22. Cantalupo PG, Katz JP, Pipas JM. Viral sequences in human cancer. Virology. 2018;513:208-16.

23. Eliassen E, Lum E, Pritchett J, Ongradi J, Krueger G, Crawford JR, et al. Human herpesvirus 6 and malignancy: a review. Frontiers in oncology. 2018;8:512.

24. Kleihues P, Cavenee W. WHO classification of tumours. Pathology \& genetics Tumors of the nervous system Lyon, France: IARCpress. 2000.

25. Cao S, Wendl MC, Wyczalkowski MA, Wylie K, Ye K, Jayasinghe R, et al. Divergent viral presentation among human tumors and adjacent normal tissues. Scientific reports. 2016;6(1):1-12.

26. Martínez-López JL, Torres J, Camorlinga-Ponce M, Mantilla A, Leal YA, Fuentes-Pananá EM. Evidence of Epstein-Barr virus association with gastric cancer and non-atrophic gastritis. Viruses. 2014;6(1):301-18.

27. Owens SR, Walls A, Krasinskas AM, Rund CR. Epstein-Barr virus gastritis: rare or rarely sampled? A case report. International journal of surgical pathology. 2011;19(2):196-8.

28. Zhang Y, Molot R. Severe gastritis secondary to Epstein-Barr viral infection: unusual presentation of infectious mononucleosis and associated diffuse lymphoid hyperplasia in gastric mucosa. Archives of pathology \& laboratory medicine. 2003;127(4):478-80.

29. Zong-ming EC, Shah R, Zuckerman GR, Wang HL. Epstein-Barr virus gastritis: an underrecognized form of severe gastritis simulating gastric lymphoma. The American journal of surgical pathology. 2007;31(9):1446-51.

30. Aqel N, Tanner P, Drury A, Francis N, Henry K. Cytomegalovirus gastritis with perforation and gastrocolic fistula formation. Histopathology. 1991;18(2):165-8.

31. Howaizi M, Abboura M, Sbai-Idrissi MS, Djabbari M, Auberger E. Cytomegalovirus-associated perforated gastric ulcer healing under antiviral therapy. Digestive diseases and sciences. 2002;47(10):2380.

32. Marques S, Carmo J, Pinto D, Bispo M, Ramos S, Chagas C. Cytomegalovirus disease of the upper gastrointestinal tract: a 10-year retrospective study. GE-Portuguese Journal of Gastroenterology. 2017;24(6):262-8.

\section{Tables}

Table 1 Demographic and clinical analysis combining with real-time PCR 


\begin{tabular}{|llll|}
\hline & $\begin{array}{l}\text { Gastric cancer } \\
(\mathrm{n}=50)\end{array}$ & $\begin{array}{l}\text { Chronic gastritis } \\
(\mathrm{n}=105)\end{array}$ & P-value \\
\hline $\begin{array}{l}\text { Age (Years) } \\
\text { Median (IQR) }\end{array}$ & $63(30-85)$ & $45(15-79)$ & \\
Gender & $37(72.5 \%)$ & $53(50.5 \%)$ & \\
N (\%) & $13(25.5 \%)$ & $52(49.5 \%)$ & 0.017 \\
\hline Gastric Tissues & Positive Samples & \\
& $\mathrm{N}(\%)$ & & 0.000 \\
\hline EBV & & $20(19 \%)$ & 0.779 \\
& $30(60 \%)$ & & 0.264 \\
\hline CMV & $7(14 \%)$ & $13(12.3 \%)$ & \\
\hline HHV-6 & $9(18 \%)$ & $16(15.2 \%)$ & \\
\hline
\end{tabular}

Table 2 Results of viral copies number in both GC and gastritis groups

\begin{tabular}{|lllll|}
\hline & $\begin{array}{l}\text { Gastric cancer } \\
\text { Copies/ug DNA }\end{array}$ & $\begin{array}{l}\text { Adjacent Normal } \\
\text { Copies/ug DNA }\end{array}$ & $\begin{array}{l}\text { Chronic gastritis } \\
\text { Copies/ug DNA }\end{array}$ & $\begin{array}{l}\text { Adjacent Normal } \\
\text { Copies/ug DNA }\end{array}$ \\
& Median (IQR) & Median (IQR) & Median (IQR) & Median (IQR) \\
\hline EBV & 668.9 & 103.3 & 886.0 & 177.8 \\
& $(11.65-53591)$ & $(0.000-5396)$ & $(101.0-7511)$ & $(21.90-1235)$ \\
CMV & 1296 & 92.21 & 100.0 & 0.000 \\
& $(62.60-14920)$ & $(0.000-14.93)$ & $(23.08-285.7)$ & $(0.000-14.60)$ \\
& 246.5 & 0.000 & 1594 & 26.00 \\
HHV-6 & $(21.99-21933)$ & $(0.000-12294)$ & $(140.3-27493)$ & $(0.000-2561)$ \\
\hline
\end{tabular}

\section{Figures}


Gastric cancer

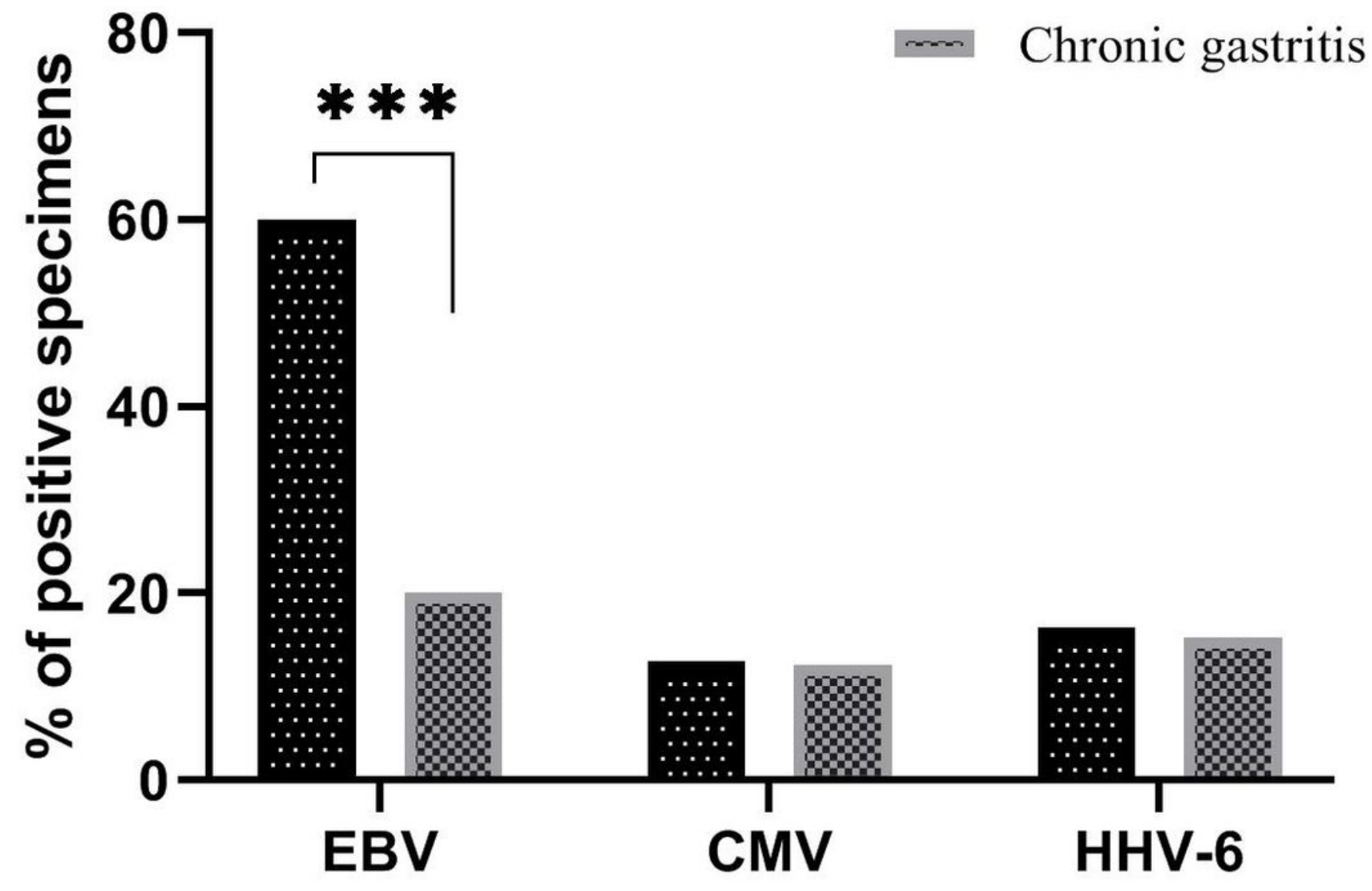

Figure 1

The frequency of EBV, CMV and HHV-6 in GC and gastritis tissues specimens were measured by using real-time PCR. 


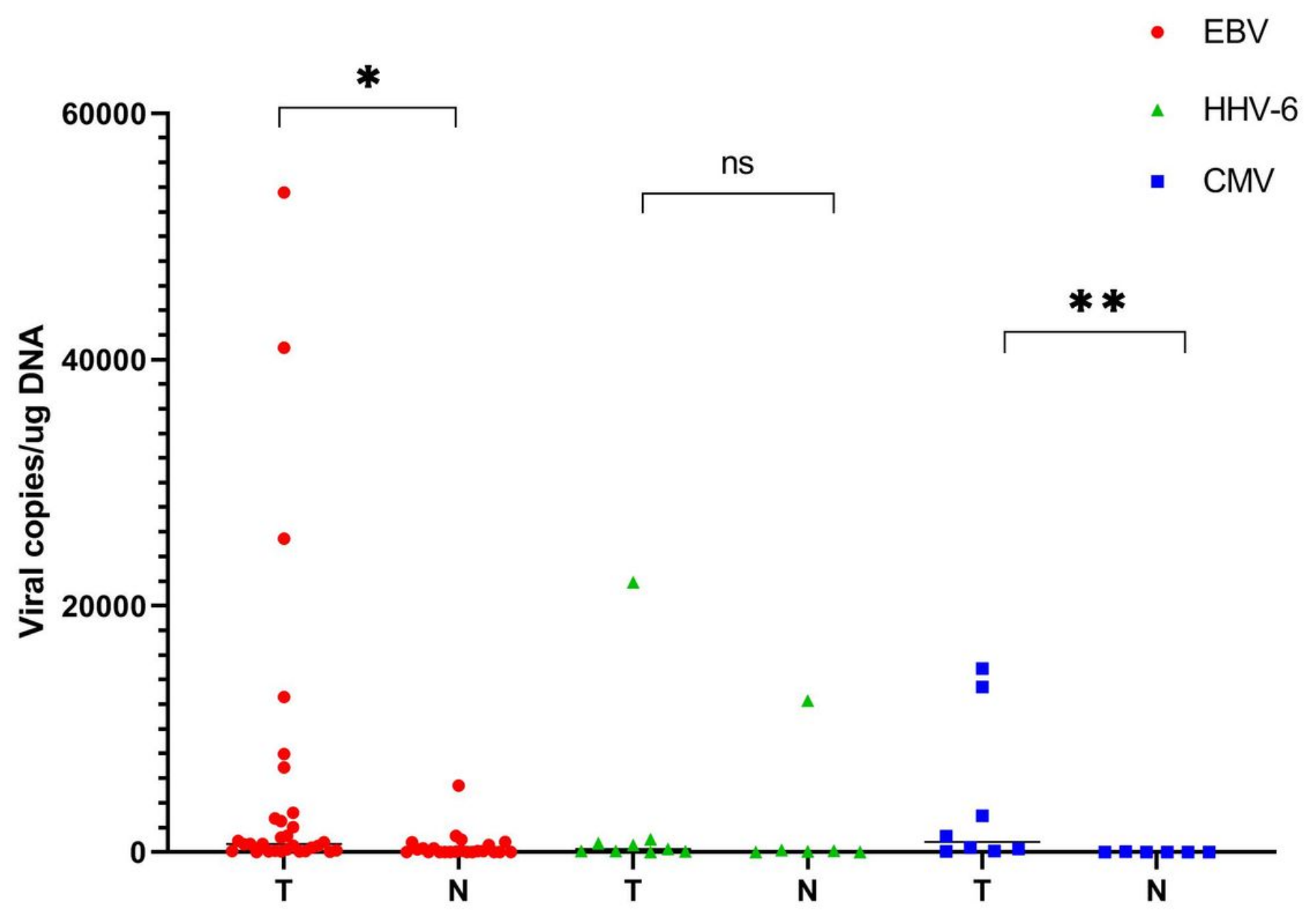

Figure 2

Comparative viral copies analyzed by quantitative real-time PCR in the tumor $(\mathrm{T})$ and adjacent normal $(\mathrm{N})$ specimens of GC. 


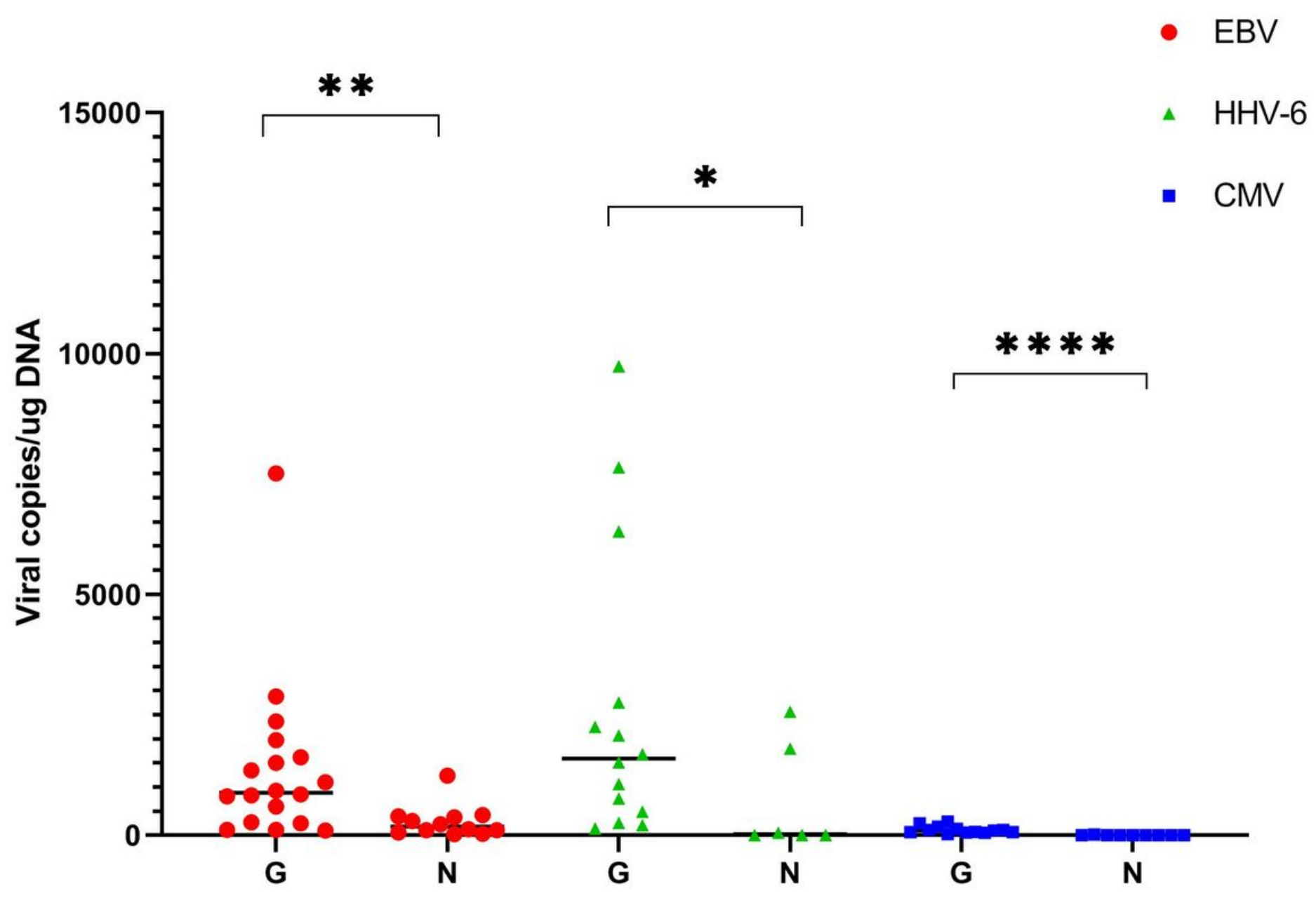

Figure 3

Comparative viral copies analyzed by quantitative real-time PCR in the gastritis lesion (G) and adjacent normal $(\mathrm{N})$ specimens of gastritis. 